\title{
A visão da massa por Paul Tillich e Juan Luis Segundo
}

\author{
Eduardo Gross*
}

\begin{abstract}
RESUMO
A perspectiva de Paul Tillich a respeito do moderno fenômeno da massa como uma configuração humana pretende ser uma crítica da depreciação protestante e burguesa tradicional em relação a ele. Seu texto Masse und Geist, de 1922, possui, nesse sentido, uma relação com a sua teologia da cultura, reivindicando uma relação próxima da liderança popular com o espírito cultural da massa. Mas uma apreciação inocente do espírito da massa - cujos perigos se tornaram claramente exemplares após a queda da república de Weimar - deveria ser evitada. A crítica de Segundo ao comportamento de massa ajuda a enfatizar o valor da personalidade e a importância de processos culturais pedagógicos.
\end{abstract}

Palavras-chave: massa; personalidade; Tillich; Segundo

\section{MASS ACCORDING TO PAUL TILLICH AND JUAN LUIS SEGUNDO}

\begin{abstract}
Paul Tillich's perspective on mass modern phenomenon as human configuration aims to be a critique of traditional protestant and bourgeois depreciation in relation to it. His text Masse und Geist, of 1922, presents a relation to his theology of culture, pleading for a close relation of popular leadership to the cultural spirit of the mass. Notwithstanding, a naive appraisal of the spirit of the mass - whose dangers became exemplary clear after the fall of Weimar's republic - should be avoided. Segundo's critique of mass behavior helps to emphasize the value of personality and the importance of cultural pedagogical processes.
\end{abstract}

Key words: mass; personality; Tillich; Segundo

* Bacharel e doutor em teologia pela EST-RS; professor da UFJF; eduardo.gross@ufff.edu. br; http://lattes.cnpq.br/2654429053268264.

https://orcid.org/0000-0002-6179-2633 


\section{Introdução}

No contexto da tematização do centenário da conferência de Tillich sobre teologia da cultura, é interessante lançar o olhar também para outros textos temporalmente próximos daquela conferência, objetivando compreender a sua proposta contextualmente. É nesse sentido que aqui se propõe um exame especificamente do texto Masse und Geist (Massa e espírito), de 1922. A pergunta pela relevância atual de uma abordagem como a desse texto de Tillich convida a um diálogo com outra abordagem do tema da massa, para o que se traz aqui a perspectiva de Juan Luis Segundo, de certo um dos autores que mais se ocupou do tema no contexto latino-americano. Como pano de fundo, tanto do contexto de Tillich como do atual, em que pesem grandes diferenças, um elemento comum é o da disseminação apaixonada de perspectivas simplistas que tomam conta de grandes contingentes humanos, em boa parte em função da linguagem rápida e superficial das mídias sociais, sendo particularmente notável o avanço de perspectivas de extrema-direita e de teorias conspiratórias. Em razão da limitação que uma exposição como esta precise respeitar não será possível desenvolver aqui detalhamentos quanto a isso, mas a intenção é de que essa situação contextual permaneça presente ao se refletir sobre o tema.

\section{Massa e personalidade em Paul Tillich}

O período da passagem do século 19 para o século 20 representa, dentre tantas outras transformações radicais, uma mudança com relação ao adensamento populacional, à sua concentração urbana e à participação destes contingentes na vida política e cultural de uma forma mais direta do que anteriormente. De um modo geral, é possível dizer que os dirigentes políticos e eclesiásticos tradicionais foram tomados de certo embaraço e mesmo incômodo com essa situação nova. Pensadores como Nietzsche, Heidegger, Ortega y Gasset e Simmel, dentre tantos outros, podem ser vistos como exemplos de tentativas criativas de lidar com a dimensão de despersonalização que caracteriza aquele momento. O próprio surgimento dos estudos sociológicos talvez possa ser bem compreendido a partir dele. É preciso reconhecer, ao mesmo tempo, que o fenômeno em si continuou se aprofundando desde então, 
o que mantém a relevância da questão e a visita a esses autores que de diversas formas o encararam.

Também Tillich ousou dizer algo sobre essa situação, tentando evidenciar aspectos importantes para a valorização da transformação em curso. No início de seu texto Masse und Geist, de 1922, ele afirma:

[...] o problema da massa, compreendido em profundidade, é o próprio problema do espírito, e não um tema de ódio ou de sentimentalismo, [...] e todo emprego do termo "massa" como uma divisa é não só uma injustiça social, mas também uma culpa em relação ao espírito ${ }^{1}$ (Tillich, 1962 [1922], p. 35).

Ou seja, é bem notório aqui que Tillich esteja se contrapondo ao tipo de temor conservador diante da realidade de que as massas estejam ocupando um espaço novo no âmbito social, político e cultural. Exatamente o âmbito cultural é o que vai ser privilegiado nesse texto, justamente porque esse é, para Tillich, o âmbito de manifestação do espírito. Assim, o texto está divido em três partes: Massa e personalidade (em que a discussão com a arte e com o ideal antropológico protestante e burguês são centrais), massa e formação, massa e religião.

A análise da relação entre massa e personalidade na sua representação artística, no caso pictórica, pontua diferentes momentos histórico-artísticos: no medievo, a massa e a liderança não se distinguem por suas individualidades, mas por alguns elementos formais que denotam autoridade; no renascimento, as individualidades são ressaltadas, particularmente com o uso de caretas que simbolizam determinadas situações pessoais; no barroco um poder metafísico natural perpassa a todos, sendo o burguês a representação do poder; no modernismo, há uma contraposição entre impressionismo, que destaca a exterioridade com desprezo pela massa, e expressionismo, em que as individualidades são descaracterizadas, a liderança surge da massa sem se destacar dela e uma mística massiva não sobrenatural, ainda que sobre-humana, se manifesta. Sintetizando o conjunto de sua visão desses diversos momentos, Tillich

1 “[...] daß das Problem der Masse, in der Tiefe erfaßt, das Problem des Geistes selbst ist und nicht eine Sache des Hasses oder der Sentimentalität, [...] und daß jeder schlagwortartige Gebrauch des Wortes "Masse" nicht nur ein soziales Unrecht, sondern eine Schuld ist am Geiste selbst." 
aponta para três tipos de apreciação da massa: místico (cf. medieval), técnico (burguês moderno) e dinâmico (sintético, expressionista) (Tillich, 1962 [1922], p. 36-41).

Como um paralelo no âmbito do ideal de personalidade, Tillich apresenta o que pode ser considerado como uma concepção que caracteriza a modernidade burguesa e, paralelamente, protestante. Aqui é ressaltado o conceito de personalidade. $\mathrm{O}$ uso desse termo precisa ser destacado. Muitas vezes se apresentam críticas ligeiras ao individualismo moderno, burguês e protestante. O conjunto do texto de Tillich também critica um simples favorecimento do individualismo. Mas o uso do termo personalidade aponta para a importância de não se perder a dimensão pessoal em meio à massa. A definição que ele apresenta é a da “[...] elevação de uma individualidade a um portador autônomo de valores válidos."2 (TILLICH, 1962 [1922], p. 41). Ou seja, uma personalidade representa uma liderança que expressa os aspectos formais da vida em geral, mas não se reduz a eles. Ela é simultaneamente portadora de um conteúdo, de uma substância, de uma palavra [Gehalt, Wort] que representa um posicionamento diante da realidade (TILLICH, 1962 [1922], p. 42).

O conteúdo é um posicionamento último diante da realidade, uma sensação imediata da vida e do mundo, uma experiência do incondicionado-verdadeiro que fornece sentido, fundamento e suporte para tudo e que, ele mesmo, entretanto, não é "algo", não é uma forma ao lado ou acima das demais, mas é o significado, a substância, a "força" de qualquer forma. O conteúdo é imediato, irrefletido, inconsciente $[\ldots]^{3}$. (TILLICH, 1962 [1922], p. 42).

Ou seja, com esse conceito de personalidade se expressa um tipo de noção que visa superar a concepção meramente formal de individualidade, que teve sua origem no Renascimento e na Reforma, vindo a caracterizar a modernidade. A importância do "conteúdo" da personalidade, da "substância" que a torna portadora de valores resgata a importância dessa

\footnotetext{
2 “[...] die Erhebung einer Individualität zu einem selbstäntigen Träger gültiger Werte.”.

3 "Der Gehalt ist eine letzte Einstellung zur Wirklichkeit, ein unmittelbares Lebens- und Weltgefühl, ein Erfahren des Unbedingt-Wirklichen, das allem Sinn, Grund und Halt gibt und selbst doch nicht "Etwas" ist, nicht eine Form neben oder über anderen, sondern die Bedeutung, die Substanz, die "Kraft" jeder Form ist. Der Gehalt ist unmittelbar, unreflektiert, unbewußt [...]"”
} 
figura diante da indiferenciação que a pura massa significa sem defender um elitismo que divorcia a liderança do conjunto social ${ }^{4}$. Enquanto que a modernidade burguesa e o protestantismo cultivaram a noção de que pela formação (Bildung) se poderia desenvolver tais personalidades que portassem os valores da civilização, imprimindo-se assim uma forma à massa informe, Tillich pensa numa relação dinâmica entre a liderança e a massa no sentido de uma representação viva de sua inter-relação.

Mas o líder guia não se posiciona para além da massa; pois ele vive da mesma substância que a massa porta consigo e é líder guia só pelo fato de que ele a manifesta em si de um modo mais forte, consciente. Ele porta os símbolos que são válidos para todos; ele mesmo é um símbolo, e por através dele resplandece o conteúdo do todo, que é maior do que $\mathrm{ele}^{5}$ (TILLICH, 1962 [1922], p. 45).

Essa citação mostra bem a relação profundamente coerente dessa concepção de Tillich com o seu pensamento em geral e ilustra bem o seu ideal político-cultural. Ao mesmo tempo, ela mostra a impossibilidade de se utilizar essa linguagem na atualidade, assim como os perigos que ela contém.

Que essa concepção de Tillich não seja uma simples especulação abstrata, mas se expresse na história do desenvolvimento do protestantismo, ele exemplifica com dois padrões de personalidade ética que caracterizaram as teologias da Reforma. No âmbito do luteranismo, o modelo foi o da ética do dever, que pressupõe o respeito às instituições e a seus representantes constituídos. O ideal da personalidade ética, nesse modelo, na prática descarta um papel ativo da massa. Tillich, em observação cáustica, o chama de "ética do funcionário", sendo que ela caracteriza o conjunto da estrutura social, desde o mandatário político até o mais inferior subalterno. O modelo preconizado no veio luterano na Reforma Tillich enxerga reproduzido também em sua época, mesmo em partidos e sindicatos. Em contraponto, no âmbito do calvinismo, o modelo é de uma ética democrática. Entretanto, trata-se na prática de

4 Cabe observar, entretanto, que nesse contexto Tillich utiliza um termo hoje impossível de ser resgatado por motivos óbvios: "a personalidade líder, guia” (Führerpersönlichkeit).

5 "Der Führer aber steht nicht jenseits der Masse; lebt doch auch er von derselben Substanz, die die Masse in sich trägt, und ist Führer nur dadurch, daß er sie kräftiger, bewußter in sich darstellt. Er trägt die Symbole, die für alle gültig sind; er ist selbst Symbol, und durch ihn hindurch leuchtet der Gehalt des Ganzen, das größer ist als er." 
uma democracia que expressa a elite burguesa e igualmente não representa a massa. Isso porque a ênfase na predestinação leva por um lado ao isolamento do indivíduo, e, por outro lado, faz com que a pessoa busque com seu empenho pessoal demonstrar o seu caráter diferenciado em relação à massa (perditionis, poderia ser acrescentado). A questão é que tal ênfase individualista prejudica a visão da personalidade como portadora de valores universais. (TILLICH, 1962 [1922], p. 47-49).

Diferentemente do ideal burguês de formação intelectual e do ideal protestante de formação moral da personalidade líder, em acordo com a sua concepção geral de interação entre forma e conteúdo ou substância, Tillich entende que a elevação da personalidade líder a partir da massa é um processo que não se pode reduzir a um mecanismo formal, como é o caso de um processo pedagógico ou educacional. A solução não se dá por via formal, mas através do surgimento de um Gehaltstypus - uma personalidade dotada de conteúdo, de substância. Ou seja, trata-se de um acontecimento - aliás, coletivo - e não de um processo deliberado ou planejado. Pode-se pensar, aqui, em como surgem líderes políticos, por exemplo. Por mais que haja formação escolar ou administrativa, tais lideranças efetivamente surgem, sendo que sua liderança é simplesmente reconhecida. Nesse sentido, não se trata aqui de algo que pode ser comprovado, mas é algo intuído - ou se crê ou não na mensagem de que uma liderança é portadora. O problema da noção burguesa moderna é que sua abordagem crítica é destrutiva da tradição - massiva - a partir da qual a liderança surge. E o problema da noção ética protestante é que ela tende a absolutizar princípios e a se tornar moralismo. Ambas as posições se contrapõem à massa de modo puramente crítico, de modo que uma concepção mística da massa revela o necessária contraponto: nela não são alguns sujeitos que tornam os outros objetos, mas todos são portadores e expressão de um conteúdo fundamental (Gehalt). Ainda que em cada âmbito da vida algumas pessoas sejam mais "massa" ou mais "líder", num contexto em que haja um conteúdo fundamental comum (o que em outros textos Tillich expressa com o termo teonomia), o sentido compartilhado torna natural o compartilhamento também de tarefas de liderança e de subordinação. Com isso se supera a distinção entre pessoa formada e leiga. E isso também se contrapõe a uma liderança que assuma sua tarefa de um modo meramente instrumental, de modo 
a objetificar a massa em seu próprio interesse. O lider guia ("Führer") deveria unir a potencialidade intelectual-intuitiva da dimensão cultural (“Geistigkeit") com a dimensão volitiva-heróica-ética, representando assim a personalidade ideal (TILLICH, 1962 [1922], p. 49-56). E, nesse sentido, Tillich emprega a palavra fé, mostrando como esse termo diz respeito à vida cultural e espiritual que caracteriza a sociedade, assim como ele tem nesse contexto também falado de uma "massa mística".

O líder guia sem fé [isto é, sem fé na substância da cultura de onde ele mesmo surgiu] é a perdição da sociedade; pois em lugar da 'fé' entra o interesse que é transformado em utilitário do poder $^{6}$ (TILLICH, 1962 [1922], p. 56).

Perceba-se aqui o caráter anti-maquiavélico da concepção tillichiana. Este acontecimento exige uma espera, ele não é simplesmente produto de um processo calculado. A tentativa de criar tal acontecimento é ela mesma sintoma de uma época produtivista. Em síntese:

Assim, todas as questões levam a esta uma resposta: que a partir da profundidade de um conteúdo novo deve nascer a humanidade em que o contraponto entre massa e personalidade esteja superado. Mas um novo conteúdo é graça e destino ${ }^{7}$ (TILLICH, 1962 [1922], p. 56).

\section{Massa, formação e religião}

As considerações anteriores mostram um posicionamento crítico de Tillich em relação à tradição elitista que foi assumida tanto pela visão burguesa quanto pela tradição protestante. Essa crítica visa uma desacomodação em relação ao lugar comum que tinha caracterizado a compreensão das camadas dirigentes, fossem elas do âmbito político, educacional ou eclesiástico. Nesse sentido, a perspectiva do texto pode ser aproximada da que se encontra no texto $O$ princípio protestante e a situação do proletariado, onde Tillich constata o distanciamento das massas em relação à forma tradicional da mensagem eclesiástica e

\footnotetext{
6 “Der 'ungläubige' Führer ist das Verderben der Gesellschaft; denn an Stelle des 'Glaubens' tritt das Interesse, dem die Macht dienstbar gemacht wird."

7 "So treiben alle Fragen zu der einen Antwort: daß aus der Tiefe eines neuen Gehalts die Menschheit geboren werden muß, in welcher der Gegensatz von Masse und Persönlichkeit überwunden ist. Ein neuer Gehalt aber ist Gnade und Schicksal."
} 
a miopia que significa o desprezo das direções eclesiais em relação às demandas que a situação efetiva da massa impõem ${ }^{8}$.

Entretanto, esse tipo de crítica também não implica simplesmente uma idealização da massa. Essa é caracterizada por ele como lugar de manifestação do poder biológico e inconsciente. Apesar disso, também nesse lugar se expressa criatividade cultural ("geistig", literalmente, "espiritual”). Embora seja na personalidade individual que a inteligência supere o biológico e o inconsciente se manifeste, ainda assim a massa pode ser mais genial, uma vez que ela opera por intuições, muitas vezes grandiosas. Embora sempre sujeitas à ambiguidade, que pode ser trágica. "Se o indivíduo é mais inteligente, então a massa é mais genial. Se o indivíduo é mais sábio, a massa é melhor e é pior. Também aqui vale a lei da indiferença de valor. A elevação pode levar ao monumental e ao heroico, mas igualmente ao demônico e ao destrutivo." (TILLICH, 1962 [1922], p. 58). O que ocorre é que, quando uma dada sociedade perde a conformação cultural que implica um reconhecimento coletivo imediato de seu valor de ser (o que em outros contextos ele chama de teonomia), surge uma objetificação da massa em contraposição à subjetividade criadora. A subjetividade crítica opera dissolução em todos os âmbitos sociais, à medida que é ela própria elevada ao aperfeiçoamento de si mesma, pelo processo reflexivo. Mas com isso essa subjetividade também perde a força da criatividade imediata (TILLICH, 1962 [1922], p. 58-60).

Nesse contexto da ambiguidade que caracteriza a massa, Tillich apresenta uma diferenciação entre massa mecânica, dinâmica e orgânica. A primeira é aquela cujas propriedades são sua passividade e instrumentalização no âmbito cultural. Em contraposição, a segunda é aquela que se contrapõe à formação cultural dominante (novamente, cultural aqui traduz "geistig", literalmente, espiritual). O seu líder guia ("Führer") expressa em sua representatividade a dimensão espiritual e cultural profunda da massa, sem se utilizar dela de um modo meramente instrumental (nova-

8 TILLICH, 1992 [1931], cap. 11. O texto está publicado na obra $A$ era protestante, mas originalmente foi publicado em 1931.

9 "Ist der Einzelne klüger, só ist die Masse genialer. Ist der Einzelne weiser, só ist die Masse böser und besser. Auch hier gilt das Gesetz der Wertindifferenz. Die Steigerung kann ins Monumentale und Heroische führen, ebenso aber auch ins Dämonische und Zerstörende." 
mente, a contraposição ao modelo maquiavélico). Para mostrar que não se trata de uma simples especulação, Tillich arrola como exemplos dessa situação o Cristianismo primitivo, o movimento das migrações bárbaras ao final do Império Romano, a Reforma e, na sua própria época, o movimento socialista. A massa orgânica, por outro lado, significa a própria superação da situação de massa - ou, conforme a terminologia comum de Tillich em outros textos, a reinserção da massa em uma situação de nova teonomia (TILLICH, 1962 [1922], p. 60-62).

É a partir desse pano de fundo analítico que Tillich discute então a educação da massa. Em primeiro lugar, a implicação é no sentido da crítica de uma noção de formação da massa em que esta seja objetificada, a partir de um saber privativo de elites do conhecimento. Concomitantemente, também não caberia uma formação de elites das massas, o que significaria uma reprodução do modelo de formação elitista burguês a um pequeno grupo dentre a massa e efetivamente condenaria a maioria à perdição. O que ele propõe, então, é uma formação que resgate positivamente os elementos culturais concretos com vista ao resgate da dimensão espiritual e cultural profunda (TILLICH, 1962 [1922], p. 63 65). Em conexão com essa proposta está também a concepção de que a liderança ("Führer") de uma massa dinâmica deve ter uma relação imediata com o espírito e a cultura da massa, superando assim a distância crítica que caracteriza a elite com formação tradicional ("Gebildete"). O fundamental nessa proposta é a percepção de que problematização e distinção caracterizam o espírito burguês, que deveria ser superado no desenvolvimento da massa dinâmica. A dimensão monumental e heroica aparecem então como aquilo a ser almejado (TILLICH, 1962 [1922], p. 65-68). Na prática, de fato acaba aparecendo a necessidade de formação de uma vanguarda. Entretanto, essa deve ser expressão do espírito cultural geral que supera as polaridades que caracterizam a massa na situação burguesa:

[ ] deve-se torná-la em certa medida um pelotão avançado daqueles que ajudam a massa a encontrar a palavra com a qual ela se liberta do caráter inconsciente em relação à dinâmica a que está submetida e com a qual ela se torna massa orgânica, isto é, massa que se superou e se libertou. [...--] Formação, aqui, quer dizer ser moldado em seu local e em sua tarefa por meio do espírito que é portador do todo e que o perpassa, o qual é 
simultaneamente universal e individual, objetivo e subjetivo ${ }^{10}$ (TILLICH, 1962 [1922], p. 69).

No que diz respeito à compreensão da relação entre massa e religião, é muito interessante que Tillich parta da distinção entre uma valorização da sacralidade intrínseca à própria massa e uma diferenciação entre massa e personalidade que prioriza a dimensão ética do religioso vivenciada de modo pessoal. A primeira compreensão ele relaciona com uma concepção mística da participação da massa na substância divina e a exemplifica, em certa medida, com a noção católica. A segunda ele liga ao caso do protestantismo. Trata-se, pois, de uma outra forma de expressão de noções como "substância católica e princípio protestante区 ou "mística e ética ou profetismo" que aparecem em outros textos seus, aqui aplicadas à questão da massa (cf. TILLICH, 1962 [1922], p. 78-81). Quando, também na formação cultural moderna (burguesa e protestante), a massa se contrapõe à personalidade individualmente formada, se enfatiza a perspectiva de uma massa perditionis. Mas ele ressalta a inadequação dessa visão, já que nenhuma forma individual pode ser expressão plena do que é incondicional. Cada forma sempre é simultaneamente afirmação e negação do relativo que busca ser expressão do incondicional (TILLICH, 1962 [1922], p. 70-72). Com isso se expressa a crítica à redução que significa a absolutização personalista protestante, particularmente em suas manifestações mais individualizantes, como por exemplo no pietismo.

Assim, é necessário enfatizar a complementaridade entre a dimensão massiva e a personalista quando se pensa a religião. Se a imersão na massa engendra uma perda da personalidade individual, por outro lado ela possibilita uma participação imediata no conteúdo substancial que não está à disposição do indivíduo da mesma maneira (TILLICH, 1962 [1922], p. 73-74). Justamente a ambiguidade desse processo revela interdependência dos dois aspectos: "[ ]" vox populi vox dei', ainda que ela seja "vox diaboli", pois ela é "vox fati”, do destino que está além do

10 “[...] sie gewissermassen zu einem Vortrupp derer zu machen, die der Masse das Wort finden helfen, in dem sie sich erlöst von der Unbewusstheit ihrer drängenden Dynamik und organische, d. h. aufgehobene erlöste Masse wird." [...---] "Bildung heisst hier: an seinem Platz und in seiner Aufgabe geformt sein durch den das Ganze tragenden und durchdringenden Geist, der universell und individuell, objektiv und subjektiv zugleich ist." 
bem e do mal, além da contraposição entre a afirmação da forma e a sua negação, e é revelação imediata do próprio conteúdo substancial puro. ${ }^{11}$ (TILLICH, 1962 [1922], p. 74). Assim, a história se desenvolve numa dinâmica em que as personalidades individuais são fundamentais enquanto portadoras de ideias e vontades, mas estas precisam ser preparadas inconscientemente no âmbito da massa. É necessário que haja uma potencialidade de recepção das ideias e vontades expressas por aquelas personalidades significativas. Sem isso, ideias e vontades não têm possibilidade de efetivação. Tais personalidades não conseguem realizar suas propostas sem uma relação de participação com a massa (TILLICH, 1962 [1922], p. 75-76). Expresso em categorias teológicas: "O indivíduo é meio de revelação, a massa é intermediadora do destino." (TILLICH, 1962 [1922], p. 72).

Ao analisar o desenvolvimento histórico da religião no ocidente desde a Reforma, Tillich entende que o protestantismo quebrou a continuidade que caracterizava a substancialidade católica, mas por seu conservadorismo não deu espaço efetivo à massa. Ele se voltou à imanência, entrou em consonância com a filosofia e a arte, mas sempre privilegiando as personalidades de formação elitista. Uma religião de massa só se manifestou a partir do Iluminismo, com os exemplos da Revolução Francesa e do movimento socialista. Essa religião de massa se insurgiu contra as autoridades religiosas e adotou um paradigma científico como seu símbolo de autoridade - o que por sua vez cria uma tensão entre a necessidade de certeza imediata pressuposta pela prática revolucionária e a incerteza intrínseca à provisoriedade metodológica do saber científico. Percebe-se aqui o uso do termo "religião" para esses movimentos alegadamente secularizados, de modo similar ao que mais tarde Tillich chamará de "quase religião". Em todo caso, sua intenção é justamente revelar a dimensão religiosa que se encontra obscurecida pelo discurso muitas vezes anti-clerical ou anti-eclesiástico. Sinais desse caráter religioso são a comunitariedade, a confiança no desenrolar do processo histórico, a fé na razão como guia, a importância da dedicação

11 “[...] 'vox populi vox dei', auch wenn sie 'vox diaboli' ist, denn sie ist 'vox fati', des Schicksals, das über Gut und Böse steht, über dem Gegensatz von Formbejahung und Formverneinung, und unmittelbare Offenbarung des reinen Gehaltes selbst." 
pessoal - e a correspondente cobrança de engajamento por parte dos companheiros (TILLICH, 1962 [1922], p. 83-85).

Mas essa religião secularizada da massa manifesta uma contradição ao se negar a reconhecer a transcendência em relação à realização histórica, imanente. É a afirmação da dimensão transcendente que impede que a ação histórica seja reduzida simplesmente a uma questão tática (mais uma vez percebe-se aqui o caráter anti-maquiavélico). Uma segunda contradição está na falta de reconhecimento suficiente da importância da vontade. A absolutização da dimensão científica como expressão da verdade tende a obscurecer que a ação humana exige o exercício da vontade e da decisão. Esta não pode ser substituída por nenhum "dogma científico" (TILLICH, 1962 [1922], p. 86-88) - aqui é praticamente impossível não perceber uma crítica ao marxismo dogmático da época; "[ ] não se trata de uma forma que é estabelecida de modo absoluto, mas de um sentido, de um conteúdo substancial, de uma criação. Um tal símbolo ainda não está presente; a consciência da massa revolucionária oscila entre o dogmatismo e a autonomia"12 (TILLICH, 1962 [1922], p. 88).

A proposta de Tillich é o reconhecimento de certas características importantes por parte dessa religião de massa, características que continuarão presentes em sua reflexão também mais tarde: a importância de confiança e de fé na ação histórica, não simplesmente sua redução a aspectos táticos e conquistas pontuais; o reconhecimento de que a ação histórica se desenrola na polaridade entre liberdade e destino; o fato de que entre a liderança e a massa há uma relação de co-dependência que não pode se resumir ao protagonismo de um dos polos; a sacralidade como tendo um aspecto presente e um futuro, pois sem a do presente se perde o sentido e sem a do futuro se esvai a esperança; a força do termo "classe" precisa ser entendida dando expressão a sua função simbólica, de modo a superar o particularismo e o enrijecimento de estruturas partidárias e de lideranças políticas - conforme o caráter simbólico da expressão "reino de Deus" Em síntese, esse conjunto de noções que também aparecem de formas diferentes em relação a outros temas no pensamento de Tillich aponta para a esperança que, naquele momento, ele nutria no

12 "[...] nicht eine Form wird absolut gesetzt, sondern ein Sinn, ein Gehalt, eine Schöpfung. Noch ist ein solches Symbol nicht da; noch schwankt das Bewußtsein der revolutionären Masse zwischen Dogmatismus und Autonomie." 
sentido de que uma nova forma de religião de massa conseguisse conjugar novamente os dois tipos de religião - mística e ética - sem perder a relação com a imanência, mas também sem absolutizar as circunstâncias concretas (TILLICH, 1962 [1922], p. 88-90).

\section{Massas e minorias em Juan Luis Segundo}

As considerações de Juan Luis Segundo sobre a questão das massas parte fundamentalmente de três noções por ele assumidas: a distinção entre massas e minorias feita por Ortega y Gasset, a argumentação em torno da lei termodinâmica da entropia que ele relaciona com o pensamento evolucionista de Teilhard de Chardin e o personalismo de Nicolas Berdiaeff.

Em suas obras Función de la Iglesia en la Realidad Rioplatense, de 1962, e Massas e minorias, originalmente publicada em 1973, se encontram as bases argumentativas que mais tarde aparecem de forma constante, mas às vezes com menos clareza quanto à sua centralidade para a concepção teológica geral de Segundo. Na primeira obra, após uma fundamentação exegética principalmente em João e Paulo, ele apresenta o que poderia ser considerado o núcleo de sua eclesiologia:

Assim, na Igreja temos reunidas duas realidades opostas, as quais devem ser mantidas em tensão contínua: por um lado a Igreja "pequena grei", comunidade delimitada no tempo, no espaço e no número por sua própria função a serviço da comunidade humana; e por outro lado a Igreja grande como a própria humanidade, unida sem fissuras com ela, em busca de uma mesma salvação pelo mesmo caminho. ${ }^{13}$ (SEGUNDO, 1962, p. 47).

Esse núcleo de sua perspectiva vai caracterizar tanto a crítica feita às tentativas de recuperação de um ideal de cristandade como também a feita à valorização ingênua da religiosidade popular. Segundo sempre propôs uma teologia para uma igreja que se entendesse como um espaço de atuação para uma minoria autoconsciente e engajada em favor das

13 "Así tenemos reunidas en la Iglesia dos realidades opuestas, y que hay que mantener en tensión continua: por un lado la Iglesia "pequeña grey", comunidad delimitada en el tiempo, en el espacio y en el número por su misma función al servicio de la comunidad humana; y por otro lado la Iglesia grande como la misma humanidad, unida sin fisuras con ella, en busca de una misma salvación por el mismo camino." 
massas humanas. Isso não significa para ele desprezo pelas massas, mas constatação de uma obviedade: nem todas as pessoas podem se dedicar com toda a profundidade a tudo. E os valores evangélicos exigem um grau de compromisso que não é possível para todos. Tal concepção teológica se conjuga com um esclarecimento terminológico importante, que expressa o tipo de análise social que ele assume:

Em outras palavras, pareceria que, em si mesmo, o Cristianismo estivesse estruturado em oposição à dinâmica das multidões, das massas. Mas antes de seguir adiante digamos já, de uma vez por todas, para evitar mal-entendidos, que não compreendemos aqui por massas o que se chama frequentemente de massas populares, quer dizer, as classes proletárias. Entendemos a palavra massa nesse sentido que passou à linguagem comum em expressões como "homem-massa", "sociedade massificada", etc. [...---] O homem-massa é uma dimensão humana, simplesmente ${ }^{14}$ (SEGUNDO, 1962, p. 70).

Desse modo, as características da massa são a simplificação e o imediatismo, em distinção às análises e compreensões de complexidades e às perspectivas de longo prazo. (SEGUNDO, 1962, p. 72-3). E o tipo de transformação que o cristianismo possibilita não deve ser reduzido a uma revolução de massas (ainda que pontualmente não a exclua por princípio). Porque os aspectos qualitativos da transformação necessariamente devem estar em primeiro plano. (SEGUNDO, 1962, p. 79).

Em Massas e minorias essa concepção é tratada de um ponto de vista ainda mais sistemático. Segundo retoma observações adiantadas em 1935 por Ortega y Gasset, em La rebelión de las masas, de que as massas representam uma novidade histórica em que valores aristocráticos correm o perigo de se perder. Minorias aristocráticas são caracterizadas como aquelas que "[...] sabem 'exigir mais de si' do que o resto da população [...]" e que recusam "[...] a lei do menor esforço [...]"; a busca pelo menor esforço, assim como soluções fáceis e imediatas caracterizam

14 "En otras palabras, parecería que, en sí mismo, el Cristianismo estuviera estructurado en oposición a la dinámica de las muchedumbres, de las masas. Pero antes de pasar adelante digamos ya, de una vez por todas, para evitar malentendidos, que no entendemos aquí por masas lo que se llama frecuentemente masas populares, es decir las clases proletarias. Entendemos la palabra masa en ese sentido que ha pasado al lenguaje común en expresiones como "hombre-masa", "sociedad masificada", etc. [...---] El hombre-masa es una dimensión humana, simplemente." 
o que é denominado de "homem-massa" (SEGUNDO, 1975, p. 18-20). Isso é totalmente afim ao que expunha Ortega y Gasset na obra referida:

A massa é o conjunto de pessoas não especialmente qualificadas. Não se entenda, pois, por massas só nem principalmente "as massas operárias". Massa é o homem médio. Deste modo se converte o que era meramente quantidade - a multidão - em uma determinação qualitativa: é a qualidade comum, $[\ldots]$ um tipo genérico ${ }^{15}$.

Também o conceito de entropia, tomado do âmbito da física, é utilizado em Massas e minorias como argumento para embasar as noções sociológica e teológica expostas. Os pressupostos físicos assumidos são de que: a) a energia global é constante; b) a energia dos corpos complexos (como os animais, p. ex.) não é maior, mas está distribuída de um modo diferente da dos corpos simples; c) há uma tendência à degradação das formas de energia dos modelos mais complexos aos mais simples. A aplicação desse conceito pode ser sintetizada, por sua vez, em quatro pontos: a) Tudo no universo tende naturalmente ao que exige menos complexidade ou esforço; b) massas e minorias não são grandezas substantivas, mas deve-se falar em condutas de massa e condutas minoritárias, e isso em cada pessoa; c) essa lei de economia de energia é o que permite a existência de estudos sociais, que se guiam por estatística, apesar da possibilidade de liberdade do ser humano; d) condutas massivas e minoritárias estão intimamente entrelaçadas, essas são uma base necessária para o desenvolvimento inovador, criativo e evolutivo, ao passo que tais inovações precisam se dar em favor das massas para não se perderem (SEGUNDO, 1975, p. 19-25). Importante, nesse contexto, é destacar o que isso significa para a compreensão antropológica:

Em outras palavras, o próprio preço da liberdade nos planos em que queremos verdadeiramente ser livres, consiste em automatizar, em mecanizar o resto de nossa atividade segundo a linha do menor esforço. Isto significa que todos (e não um grupo especial) somos massa, agimos com comportamento de massa, na maior parte (quantitativamente) de

\footnotetext{
15 "La masa es el conjunto de personas no especialmente cualificadas. No se entienda, pues, por masas sólo ni principalmente 'las masas obreras'. Masa es el hombre medio. De este modo se convierte lo que era meramente cantidad - la muchedumbre - em una determinación cualitativa: es la cualidad común, [...] un tipo genérico."
} 
nossa atividade, e isso é exigido pela própria lei da economia da energia (SEGUNDO, 1975, p. 23).

Mas esses argumentos baseados numa observação social e numa analogia física obscureceriam a intenção fundamental de Segundo se ficasse esquecido o aspecto mais central para a estrutura do seu pensamento, que ele toma da concepção personalista de Berdiaeff. É comum a Segundo e a Berdiaeff, autor que foi objeto de sua tese de doutorado, a noção de que o Cristianismo exige uma dedicação pessoal especial, que por sua vez pressupõe a noção de liberdade como uma dimensão própria da constituição humana. Essa liberdade, entretanto, não pode ser pensada em termos abstratos, mas existe sempre só em conexão com as determinações concretas da existência. Desse modo, o exercício da liberdade pessoal sempre se dá em meio a uma realidade necessariamente conflituosa. Ao contrário de conceber a liberdade como uma conquista final, um alvo abstrato, é necessário compreendê-la como uma prática difícil, que exige sacrifício pessoal, sendo sempre muito mais fácil desistir dela do que assumi-la efetivamente (SEGUNDO, 1963; SEGUNDO, 1993, especialmente p. 99, 101, 106-107, cf. p. 208, 213-214). O que em Berdiaeff era uma concepção originalmente especulativa, fundada em leituras personalistas originadas dos círculos teológicos do catolicismo ortodoxo oriental sob inspiração dostoievskiana, foi apropriado por Segundo com ênfase numa contextualização existencialista (com pitadas importantes de elementos de Sartre e Camus), social (cf. acima, Ortega y Gasset) e universal (cf. entropia e Teilhard de Chardin).

\section{Conclusão}

Primeiramente é importante destacar o ponto comum entre a concepção de Tillich e a de Segundo no que diz respeito à apreciação das massas: o conceito de personalidade. Este conceito é fundamental para se evitar tanto a indiferenciação dos indivíduos que caracteriza as condutas massivas quanto para se evitar o enaltecimento do individualismo. A noção de pessoa é uma contribuição fundamental da tradição cristã (cf. SEGUNDO, 1985, v. II/II p. 53-55) para a reflexão antropológica. Ela é importante também porque se distingue do mito individualista do contrato social que funda a modernidade (cf. RICOEUR, 1991, p. 268ss). 
A relação entre pessoa e as noções de espírito ou cultura não pode ser reduzida a uma compreensão racionalista. Uma abordagem racionalista tende a mascarar o fato de que a ideia de contrato social é efetivamente um mito - com todo a inevitabilidade, a potencialidade e o perigo que caracteriza os mitos. Isso é importante em função de que este mito fundador da concepção moderna da constituição social está em pleno vigor e é o pressuposto básico de várias teorias sociológicas e políticas.

Tillich se contrapôs ao conservadorismo elitista de sua época ao afirmar positivamente as potencialidades que as massas significavam. A valorização da arte expressionista e a acolhida do proletariado como testemunho crítico do fracasso social e eclesial (TILLICH, 1992 [1931], cap. 11) demonstram isso suficientemente. Por outro lado, especialmente o texto Masse und Geist, privilegiado na presente exposição, mostra também os limites ainda existentes em sua reflexão no contexto do início de sua teologia da cultura. Masse und Geist, como muitos textos de Tillich, serve muito bem para interpretar a realidade, mas talvez não tanto para encaminhamentos concretos. Pelo contrário, a afinidade terminológica com um linguajar mítico massivo mostra que essa concepção não oferecia defesa suficiente para o que estava para acontecer no contexto alemão, expressando de modo forte a ambiguidade que caracterizava a avaliação e as expectativas em relação ao ambiente social e político da república de Weimar. A densidade da possibilidade analítica que o texto apresenta, por outro lado, merece ser destacada. Contrabalançando polaridades, ali se sugere a valorização da massa em uma relação esperançosa de reintegração social onde a dimensão simbólica e a racional não se excluam.

nhSegundo, por sua vez, possibilita uma saudável suspeita em relação a qualquer ilusão quanto a atividades de massa que não estejam imbuídas de suficiente espírito crítico. Se por vezes - como transparece na crítica bastante radical de Segundo à religiosidade popular, p. ex. - o pensamento de Segundo possa parecer demasiadamente elitista - ele mesmo usa positivamente o termo "élite" -, é importante resguardar a dinâmica de sua concepção, em que massas e minorias aparecem sempre como funções antropológicas e sociais que visam caracterizar a inevitabilidade de cada uma das atitudes tanto em cada pessoa quanto em cada grupo humano. A um pouco curiosa fundamentação física disso com o conceito de entropia ilustra isso bem. Ou seja, a partir de Segundo 
é possível olhar com um pouco de desconfiança para a crença demasiadamente efusiva na ação das massas. Pelo menos em comparação com algumas formulações tillichianas da época de Weimar isso parece bastante saudável.

Além disso, a preocupação pedagógica de Segundo ressalta a efetividade prática de sua intenção analítica. A intenção quase que puramente autocrítica que Tillich desenvolve em relação aos ideais de formação burguês e protestante obscurece a dependência dele próprio em relação à tradição humanista. Sua visão da formação da massa, ao valorizar as possibilidades que lhe são próprias, pode dar espaço a algum tipo de espontaneísmo ou passividade, o que de certo não era a intenção do próprio Tillich. Nesse sentido, permanece o desafio de se integrar a valorização da massa, tal como Tillich propôs no seu texto, num amplo processo pedagógico (cf. SEGUNDO, 1991; ID, 1985, v. I, p. 14-20, 9798). Esse também não deve simplesmente desmerecer os aspectos formais que são objeto da avaliação crítica por parte de Tillich - pense-se, por exemplo, na sempre imprescindível defesa das instituições formais para se resguardar tanto a democracia e o estado de direito quanto a educação de qualidade. Isso é importante para que não se descarte, mas se possa incluir a valorização da erudição pessoal, representativa de um aspecto importante dos ideais renascentista e iluminista de formação humana. Em última instância, afinal, é visível nos dois autores que uma interação entre a formação pessoal e o desenvolvimento da massa é necessária e saudável.

O contraponto aqui traçado permite olhar com algum cuidado para fenômenos como os movimentos de massa. O período imediatamente posterior ao texto de Tillich aqui apresentado foi dominado pelo nazismo e pelo fascismo, e é necessário ter em mente que estes foram efetivamente fenômenos populares de massa, inclusive abertamente hostis à cultura erudita e especialmente em relação à vanguarda artística. Aquele momento seguinte, tão próximo ao do lançamento da teologia da cultura de Tillich, se lançou exatamente na direção contrária ao da valorização da criatividade que brotava da riqueza cultural que ele preconizava. Entretanto, é importante deixar anotado que a terminologia valorizadora de um misticismo parcialmente tendente a um espontaneísmo deve ser objeto de cautela. O mesmo cuidado se aplica também para 
outros momentos em que movimentos semelhantes àqueles encontram ressonância nas massas.

Referências

ORTEGA Y GASSET, José. La rebelión de las masas, 5a . ed. Madrid : Revista de Occidente, 1935.

RICOEUR, Paul. O si mesmo como um outro. Campinas: Papyrus, 1991.

SEGUNDO, J. L. Berdiaeff. Une Réflexion Chrétienne sur la Personne. Paris : Aubier, (C)1963.

SEGUNDO, Juan Luis. Massas e Minorias na Dialética Divina da Libertação. São Paulo, Loyola, 1975 [orig. 1973].

SEGUNDO, Juan Luis. O dogma que liberta. São Paulo: Paulinas, 1991.

SEGUNDO, Juan Luis. O homem de hoje diante de Jesus de Nazaré. São Paulo: Paulinas, 1985.

SEGUNDO, Juan Luis. ¿Qué Mundo? ¿Qué Hombre? ¿Qué Dios? Santander, Sal Terrae, 1993.

TILLICH, Paul. Masse und Geist (1922). In: TILLICH, Paul. Gesammelte Werke. Band II (Christentum und Soziale Gestaltung: Frühe Schriften zum Religiösen Sozialismus). Stuttgart: Evangelisches Verlagswerk, 1962, p. 35-90. TILLICH, Paul. O princípio protestante e a situação do proletariado. In: TILLICH, Paul. A era protestante. São Bernardo do Campo: Metodista, 1992 [1931], cap. 11.

Submetido em: 27-11-2021

Aceito em: 17-1-2022 